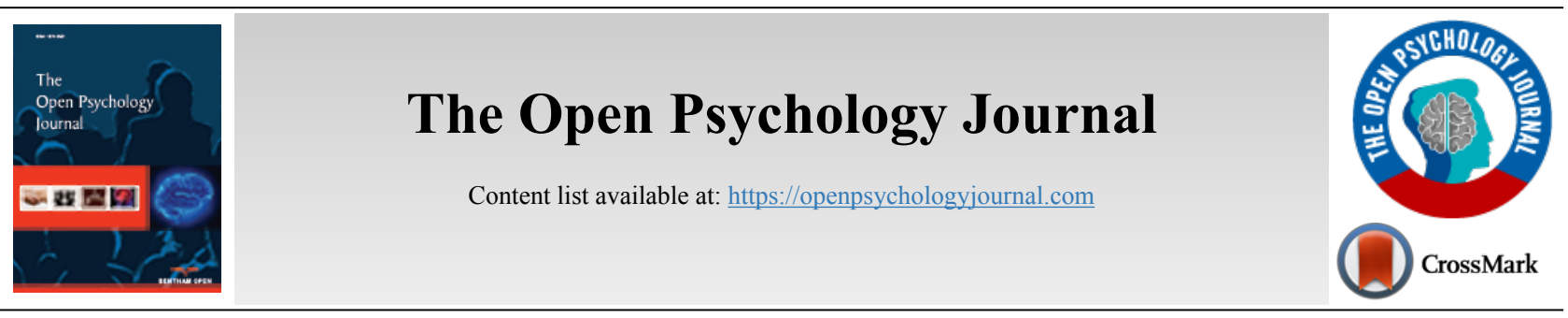

RESEARCH ARTICLE

\title{
Acculturation Process and Life Domains: Different Perceptions of Native and Immigrant Adults in Italy
}

\author{
Nadia Rania ${ }^{1, *}$, Stefania Rebora ${ }^{1}$, Laura Migliorini ${ }^{1}$ and Maria Soledad Navas ${ }^{2}$ \\ ${ }^{I}$ Departmenent of Educational Sciences, University of Genoa, Genoa, Italy \\ ${ }^{2}$ Centro de Estudio de las Migraciones y las Relaciones interculturales (CEMyRI), Universidad de Almería, Almería, Spain
}

\begin{abstract}
:
Background:

Acculturation process has taken up a relevant place in cross-cultural psychology by demonstrating the strong relationships between cultural context and individual behavioral development.

Aim:

The purpose of this study is to analyse acculturation strategies and attitudes in different life domains of native and immigrant adults living in Italy, following the Relative Acculturation Extended Model (RAEM).

\section{Methods:}

The participants were 250 Italian native and 100 immigrant adults who completed a questionnaire with items to measure their acculturation strategies (real plane) and attitudes (ideal plane), in general and related to different life domains (peripheral and central).

Results:

Results revealed that the acculturation attitude of immigrants is integration, whereas Italians prefer their assimilation.

Conclusion:

However, when different life domains are taken into account, immigrants claim to put in practice and prefer integration in most of the domains, whereas Italians perceive immigrants are separated but they prefer their assimilation or integration, depending on the specific domain.
\end{abstract}

Key words: : Acculturation strategies and attitudes, Adults, Immigrants and Natives, Acculturation domains, RAEM, Real plane.

\begin{tabular}{|l|l|l|r|}
\hline Article History & Received: October 29, 2018 & Revised: January 12, 2019 & Accepted: February 10,2019 \\
\hline
\end{tabular}

\section{INTRODUCTION}

Social psychology has framed the relationship between immigrant and native communities within the concept of acculturation. Acculturation literature has investigated the ways in which members of minority groups enter into relationships with other groups and the host society. Members of ethnic minority groups not only belong to their own ethnic group, but they also have to deal daily with the majority group of the society in which they live. In a cross-cultural psychology approach, researchers analyse the cultural changes that occur when different cultural groups come into contact [1]. Acculturation is defined as individual changes that result from direct contact with members of a different ethno-cultural group $[2,3]$. Some social psychologists in the 20 th century $[4,5]$ ela-

\footnotetext{
* Address correspondence to this author at the Department of Educational Sciences, University of Genoa, Italy; Email: nadia.rania@unige.it
}

borated models to describe individual and community reactions to intergroup contact. At first, these processes were described with a one-dimensional model [6], subsequently with a bidimensional one $[2,7,8]$. On the basis of Berry's sugges-tion, further studies developed more recent models [5, 9] by combining the concordance or discordance between the different perspectives of natives and immigrants as the element activating consensual, problematic or conflictual intercultural relationships. Later, some authors suggested a domain-specific model claiming that the acculturation process does not take place in the same way in different domains of life [10, 11]. A few years later, Navas' Relative Acculturation Extended Model (RAEM) [12] adds interesting novel elements.

RAEM tries to understand how immigrants adapt and how the natives perceive this adaptation, furthermore, RAEM proposes a differentiation between acculturation strategies and 
accul-turation attitudes. The acculturation strategies consider the real plane for each domain, specifically the acculturation options that immigrants say they put into practice within the new society versus those that the natives perceive as being put into practice by immigrants. The acculturation attitudes refer to the ideal plane, that is, the acculturation options that immigrants would choose or prefer if they could and that natives would prefer for immigrants into the host community. The RAEM affirms that acculturation is a complex and dynamic process because you need to consider different life domains, such as political and government system, work, economic, and social relations (peripheral domains), and family relations, religion and ways of thinking (principles and values) (central domains). And, in each domain different strategies and attitudes are preferred (attitudes/ideal plane) or put into practice (strategies /real plane). Furthermore, Navas and colleagues [12] studied how the outcomes of intercultural contact can vary based on the different socio-cultural contexts or domains, with which both natives and immigrants must cope. According to the authors, there are many solutions for intercultural encounters. Some solutions are more easily acquired in the peripheral domains (work or economic domains), where both hosts and immigrants tend to use integration and assimilation strategies, but there are more difficulties in the central domains (family relations, religion or ways of thinking) where immigrants put separation into practice and natives prefer their assimilation or integration. Moreover, Navas et al. [13] used RAEM ques-tionnaire to investigate acculturation strategies and attitudes for specific domains in a sample of African immigrants (from Maghreb and sub-Saharian) in Spain. The results showed how the division into domains provides more detailed information about the acculturation process. Integration was the general acculturation attitude that most frequently emerged. However, through more in-depth analysis by life domains, immigrants showed strategies ranging from assimilation in the peripheral domains to separation in the most central private domains that are symbolic and linked to ideologies. In all cases, the strategies put into practice on the real plane coincide with the attitudes preferred on the ideal plane. Only regarding economic and social domains participants claimed to put into practice assimilation. However, there was a tendency towards a "cultural synthesis" in the ideal plane: the desire to maintain friendships and customs from their country of origin, and also to adopt some aspects of the host country culture, and to interact with the natives (integration). Afterwards Navas, et al. [14] also applied the RAEM to natives in Spain in order to investigate the difference between acculturation strategies and attitudes of African immigrants and Spanish natives. The results showed an agreement between natives and immigrants outcome regarding the acculturation strategy of assimilation in peripheral domains (work or economic) and the acculturation attitude of integration in the social domain; on the contrary, the groups differed greatly in their acculturation options for the family, religion and ways of thinking (principles and values) domains. In fact, immigrants put in practice and prefer separation, while natives perceive separation but prefer assimilation or integration of immigrants. More recently, Navas and Rojas [15] used the RAEM questionnaire with other immigrant populations (Ecuadorians and Romanians), also in
Spain, in order to study the acculturation strategies and attitudes of immigrants and their relations with natives perceptions and preferences. The results indicated a general inclination for assimilation and integration in peripheral life domains both for natives and immigrants; while in the central domains native perceived separation both for the Romanians and Ecuadorians, whose choices, conversely, varied between integration and separation. In this literature framework, Miller and colleagues [16] recently tested Miller and Lim's domainspecific acculturation strategy hypothesis [17]. It affirms that individuals might use different acculturation strategies (i.e., assimilated, bicultural, separated, and marginalized) across behavioural and value domains.

Furthermore, the acculturation process of natives and immigrants has been studied in relation to several psychosocial variables: prejudiced attitudes, in-group bias, intergroup contact and perceived intergroup similarity $[15,18]$. Moreover, in the last decades there has been a growing recognition that members of the host society also have preferences for which acculturation strategy that they would like immigrants to put into practice. Recently Celeste, Brown, Tip and Matera's experimental study (2014) [19] demonstrated the causal role that perceptions of out-group acculturation preferences have in determining integration. In fact, the concordance between natives and immigrants' acculturation preferences could be an important determinant of the nature of the subsequent intergroup relationship between different groups.

\section{THE ITALIAN CONTEXT}

In the Italian context considerable research has been dedicated to the study of immigration processes both with qualitative approaches [20 - 22] and with quantitative approaches [23, 24], in particular comparing parenting styles, routines and rituals in natives and immigrants. Other research focused on the acculturation processes and adaptation. Matera et al. [25] found that the most positive attitudes of native were produced when immigrants were perceived to adopt the strategy of the majority. Recently Mancini and Bottura [26] studied the quality of the intercultural relations in central and peripheral domains, applying the RAEM to Italian and immigrant adolescents.

In Italy, there is also a wealth of literature that examines acculturation strategies and their outcomes on socio-cultural adjustment and psychological wellbeing in adolescence [26, 27], but not much research on the adult population [28, 29]. However, recent work proposes a qualitative methodology to enhance critical and intercultural dialogue in a group of young adult hosts $[25,30,31]$. Furthermore, there are some studies $[28,32]$ that investigate the role of first and second generation immigrants in culture maintenance and intercultural contact in affecting host members' intergroup attitudes. Moreover, both contact and culture adoption can influence the way in which host members perceive immigrants' sociocultural adjustment. More recently, Migliorini and colleagues [29] studied the relationships between acculturation strategies, social distance and positive feelings towards the out-group in Italian and immigrant adults. The results confirm that for the immigrant group, there is a greater perceived social distance from the host 
group than for Italians in relation to the immigrant group. The results corroborate the association between acculturation strategies, social distance and positive feelings. In fact, participants who choose integration as acculturation strategy show lower social distance, more positive feelings towards immigrants, and higher social wellbeing.

Within this conceptual framework, the analysis of different acculturation options in native and immigrant adults is relevant to propose that the acculturation strategies and attitudes change among different groups present in the same context, and among different domains in which people live.

\section{AIMS AND HYPOTHESIS}

The purpose of this research is to apply RAEM in Italy describing the general acculturation attitudes and the acculturation strategies and attitudes in different life domains (peripheral and central) in Italians and immigrants. Furthermore, to analyse by acculturation, specific domains allow to identify differences between groups and highlight potential problematic domains both from Italians and immigrants' perspective.

On the basis of the literature presented in the introduction [13 - 15], the following hypotheses have been formulated:

Hypotheses 1 (Hp1): Concerning the general acculturation attitude, Italians will prefer assimilation for immigrants, whereas immigrants will prefer integration.

Hypotheses 2 (Hp2): Acculturation strategies and attitudes will be different in peripheral and central domains. Therefore, it is expected that on the real plane, immigrants will put strategies of assimilation or integration into practice in peripheral domains of life, and they will feel more free to maintain their own culture in central domains (separation). As regards the ideal plane, it is expected that immigrants will want integration in peripheral domains and separation in central domains. Concerning natives, it is expected that on the real plane they will perceive immigrants putting assimilation into practice in the peripheral domains and separation in the central domains. Furthermore, on the ideal plane natives will desire immigrants' assimilation in every domain.

\section{METHODS}

\subsection{Participants}

Participants were 250 Italian and 100 immigrant adults (59.6\% females and $40.4 \%$ males), living in two regions of central and north-western of Italy. The Italian participants (41.6\% males and $58.4 \%$ females) are 40.5 years old (range: $28-65$ years, $S D=5.95$ ). As regards professional activity, $29.8 \%$ are employees, $17.1 \%$ are labourers, $12.7 \%$ work freelance and $11.8 \%$ are housewives. The most common qualification held among Italian participants is the high school diploma $(34.4 \%)$, followed by a middle school certificate $(17.8 \%)$ and a university degree (16.6\%).

Immigrant participants (37.4\% males and $62.6 \%$ females) are 35.86 years old (range $21-61$ years, $S D=6.97$ ) and have lived in Italy from the age of 11.3 on average. The most prevalent cultural groups are Romanian (31.9\%), Ecuadorian
(28.6\%) and Albanian (9.9\%). Other groups account for less than $4 \%$. The main occupation within this group is labourer $(28.9 \%)$, followed by domestic help $(19.6 \%)$ and housewife $(15.5 \%)$. As for qualifications, most of the foreign participants have a high school diploma (39.8\%), $18.3 \%$ attended only two thirds of high school, $15.1 \%$ finished middle school and $14 \%$ hold a university degree.

\subsection{Instruments}

In the present research the RAEM questionnaire was used prepared by Navas and colleagues for their study in a Spanish context $[13,14]$. The questionnaire was translated and back translated into Italian and then adjusted for an Italian context. The questionnaire measured general acculturation attitudes and acculturation strategies and attitudes in specific domains. There are two versions of the questionnaire, one for Italians and one for immigrants.

General acculturation attitudes. This variable is measured on the basis of two questions, the first related to the maintenance of the culture of the country of origin, the second refers to the adoption of the host culture in both versions: in the version for Italians, "Italians should let immigrants live in this country according to their customs" and "Italians should let immigrants participate fully in the life of this society"; in the version for immigrants, "People from your country of origin should live in Italy according to their customs" or "People from your country of origin should try to participate fully in the life of Italian society". Participants had to indicate, using a 5point Likert scale, the degree of agreement (5) or disagreement (1). By combining the answers to these two questions, each participant was situated in a different type of general acculturation attitude: integration, assimilation, separation /segregation, or marginalization/exclusion [12 - 14].

Acculturation strategies and attitudes in specific domains. The following questions were applied in each of the specified domains. In the present research, the focus was only on work, economic, social relations, family relations, religion, and ways of thinking (principles and values) domains.

- Italian perceptions of immigrants' acculturation strategies (real plane) are obtained by combining the following two questions: "To what extent do you believe that immigrants maintain the traditions that they had in their original culture" and "To what extent do you believe that immigrants have adopted Italian culture".

- Italian acculturation attitudes towards immigrants (ideal plane) are obtained by combining the following two questions: "To what extent would you like immigrants to keep their original culture" and "To what extent would you like immigrants to adopt Italian culture".

- Immigrant acculturation strategies (real plane) are obtained by combining the following two questions: "To what extent do you maintain your original culture" and "To what extent have you adopted Italian culture".

- Immigrant acculturation attitudes (ideal plane) are obtained by combining the following two questions: 
"To what extent would you like to maintain your original culture" and "To what extent would you like to adopt Italian culture".

The answer is on a Likert scale from 1 (not at all) to 5 ( $a$ lot). The combination of two-by-two questions leads to four different types of acculturation strategy/attitude (integration, assimilation, separation/segregation and marginalization /exclusion) [12, 15].

Moreover, the usual sociodemographic variables (e.g., sex, age, educational level, professional activity, country of birth, and age with which they arrived in the country in the case of immigrants) were measured.

\subsection{Procedure}

The participants were contacted by a letter from their children's teachers in which the aims of the study were described. Then they met the researchers at their children's school and completed the questionnaire. An assistant researcher was present to supervise data collection. The questionnaire was self-compiled but standard instructions were given at the start of the section in which people were informed that participation was voluntary, that responses were confidential, anonymous and they could be used solely for research purposes. The data collection procedure fully complied with the research ethical code of the Italian Association of Psychology, the informed consent protocol was provided to the participant when presenting the aims of the research. The researchers correctly and clearly informed participants about all aspects of the research that could have induced them not to provide their informed consent. Participants were reassured that their answers would be kept anonymous in compliance with the Italian law on privacy No.196/2003.

\subsection{Data Analysis}

Data were analysed using SPSS 18 statistical analysis program. To describe the general acculturation attitudes and the acculturation strategies and attitudes of Italians and immigrants to specific domains, the average scores and standard deviations were calculated. To include individuals into one of four acculturation options, in line with the work of Navas and Rojas [15] and Mancini and Bottura [26], t-tests for one-sample from the average value 3 were conducted for each answer. Scale scores below the value 3 in both questions indicate a marginalization/exclusion strategy/attitude; if the score for the first question (Maintenance) was higher than 3 and the score for the second question (Adoption) lower than 3, the strategy/attitude indicated was separation/segregation; if the score for the first question was less than 3 and the score for the second more than 3, the strategy /attitude was assimilation; if the score for both questions was higher than 3 , the strategy/attitude was integration; if the score for one or both questions was equal to 3, Navas and Rojas [15] proposed classifying the responses as "indeterminate". The differences between Italians and immigrants were calculated by t-test for independent samples. The effect size was described with Cohen's d coefficient.

\section{Table 1. Descriptive analysis of general acculturation attitudes for Italian and Immigrant adults.}

\begin{tabular}{|c|c|c|c|c|c|c|}
\hline \multicolumn{9}{|c|}{ General Acculturation Attitudes } \\
\hline- & Group & $\boldsymbol{N}$ & $\boldsymbol{M}$ & $\boldsymbol{S D}$ & $\boldsymbol{t}$ & $\boldsymbol{t}$ \\
\hline Maintenance & IT & 247 & 2.83 & 1.03 & \multirow{2}{*}{$-7.31^{* * *}$} & \multirow{2}{*}{345} \\
\hline- & IM & 100 & 3.72 & .97 & & \multirow{2}{*}{-.44} \\
\hline Adoption & IT & 247 & 3.98 & .78 & & \multirow{2}{*}{345} \\
\hline- & IM & 100 & 4.02 & .74 & & \\
\hline
\end{tabular}

Note. T-test significant differences for one-sample. $* * * p<.001$; IT: Italians; IM: Immigrants

Table 2. Descriptive analysis and one-sample t-test (value 3) of acculturation strategies (real plane) by domains for Italian and Immigrant adults.

\begin{tabular}{|c|c|c|c|c|c|c|c|}
\hline Real Plane & Domains & Group & $N$ & $M$ & $S D$ & $t$ & $d f$ \\
\hline \multirow{12}{*}{ Maintenance } & \multirow{2}{*}{ Work } & IT & 250 & 2.58 & 1.0 & $-6.64 * * *$ & 249 \\
\hline & & IM & 96 & 2.70 & 1.44 & $-2.05^{*}$ & 96 \\
\hline & \multirow{2}{*}{ Economic } & IT & 250 & 3.42 & 1.0 & $6.36 * * *$ & 249 \\
\hline & & IM & 97 & 3.39 & 1.12 & $3.44 * *$ & 97 \\
\hline & \multirow{2}{*}{ Social relations } & IT & 250 & 4.44 & .70 & $32.31 * * *$ & 249 \\
\hline & & IM & 99 & 3.88 & 1.0 & $8.72 * * *$ & 99 \\
\hline & \multirow{2}{*}{ Family relations } & IT & 250 & 4.04 & .84 & $19.6^{* * *}$ & 249 \\
\hline & & IM & 98 & 4.29 & .85 & $14.98^{* * *}$ & 98 \\
\hline & \multirow{2}{*}{ Religion } & IT & 250 & 4.37 & .77 & $28.1 * * *$ & 249 \\
\hline & & IM & 97 & 3.89 & 1.21 & $7.24 * * *$ & 97 \\
\hline & \multirow{2}{*}{ Ways of thinking (principles and values) } & IT & 250 & 4.27 & .80 & $24.97 * * *$ & 249 \\
\hline & & IM & 97 & 4.08 & .97 & $10.93^{* * *}$ & 97 \\
\hline
\end{tabular}


(Table $\square$ ) contd.....

\begin{tabular}{|c|c|c|c|c|c|c|c|}
\hline Real Plane & Domains & Group & $N$ & $M$ & $S D$ & $t$ & $d f$ \\
\hline \multirow{12}{*}{ Adoption } & \multirow{2}{*}{ Work } & IT & 250 & 3.40 & .91 & $7.05 * * *$ & 249 \\
\hline & & IM & 96 & 4.04 & 1.00 & $9.76 * * *$ & 96 \\
\hline & \multirow{2}{*}{ Economic } & IT & 250 & 2.72 & .89 & $-4.96 * * *$ & 249 \\
\hline & & IM & 96 & 3.69 & 1.00 & $6.7 * * *$ & 96 \\
\hline & \multirow{2}{*}{ Social relations } & IT & 250 & 3.10 & .82 & $1.99 *$ & 249 \\
\hline & & IM & 99 & 4.09 & .83 & $13.01 * * *$ & 99 \\
\hline & \multirow{2}{*}{ Family relations } & IT & 250 & 2.48 & .89 & $-9.14 * * *$ & 249 \\
\hline & & IM & 98 & 3.89 & 1.17 & $7.5 * * *$ & 98 \\
\hline & \multirow{2}{*}{ Religion } & IT & 250 & 1.94 & .94 & $-17.83^{* * *}$ & 249 \\
\hline & & IM & 96 & 3.14 & 1.37 & .97 & 96 \\
\hline & \multirow{2}{*}{ Ways of thinking (principles and values) } & IT & 250 & 2.18 & .88 & $-14.7 * * *$ & 249 \\
\hline & & IM & 97 & 3.59 & 1.24 & $4.7 * * *$ & 97 \\
\hline
\end{tabular}

Note. T-test significant differences for one-sample. ${ }^{* * *} p<.001 ; * * p<.01 ; * p<.05$; IT: Italians; IM: Immigrants

Table 3. Descriptive analysis of acculturation strategies for Italian and Immigrant adults in specific domains (real plane).

\begin{tabular}{|c|c|c|c|c|c|c|c|}
\hline Real Plane & Dimensions & Group & $N$ & $M$ & $S D$ & $t$ & $d f$ \\
\hline \multirow{12}{*}{ Maintenance } & \multirow{2}{*}{ Work } & IT & 250 & 2.58 & 1.0 & \multirow{2}{*}{-.86} & \multirow{2}{*}{344} \\
\hline & & IM & 96 & 2.70 & 1.44 & & \\
\hline & \multirow{2}{*}{ Economic } & IT & 250 & 3.42 & 1.0 & \multirow{2}{*}{.19} & \multirow{2}{*}{345} \\
\hline & & IM & 97 & 3.39 & 1.12 & & \\
\hline & \multirow{2}{*}{ Social relations } & IT & 250 & 4.44 & .70 & \multirow{2}{*}{$5.90 * * *$} & \multirow{2}{*}{347} \\
\hline & & IM & 99 & 3.88 & 1.0 & & \\
\hline & \multirow{2}{*}{ Family relations } & IT & 250 & 4.04 & .84 & \multirow{2}{*}{$-2.40 *$} & \multirow{2}{*}{346} \\
\hline & & IM & 98 & 4.29 & .85 & & \\
\hline & \multirow{2}{*}{ Religion } & IT & 250 & 4.37 & .77 & \multirow{2}{*}{$4.44 * * *$} & \multirow{2}{*}{345} \\
\hline & & IM & 97 & 3.89 & 1.21 & & \\
\hline & \multirow{2}{*}{ Ways of thinking (principles and values) } & IT & 250 & 4.27 & .80 & \multirow{2}{*}{1.85} & \multirow{2}{*}{345} \\
\hline & & IM & 97 & 4.08 & .97 & & \\
\hline \multirow{12}{*}{ Adoption } & \multirow{2}{*}{ Work } & IT & 250 & 3.40 & .91 & \multirow{2}{*}{$-.56^{* * *}$} & \multirow{2}{*}{344} \\
\hline & & IM & 96 & 4.04 & 1.00 & & \\
\hline & \multirow{2}{*}{ Economic } & IT & 250 & 2.72 & .89 & \multirow{2}{*}{$-8.70 * * *$} & \multirow{2}{*}{344} \\
\hline & & IM & 96 & 3.69 & 1.00 & & \\
\hline & \multirow{2}{*}{ Social relations } & IT & 250 & 3.10 & .82 & \multirow{2}{*}{$-10.04 * * *$} & \multirow{2}{*}{347} \\
\hline & & IM & 99 & 4.09 & .83 & & \\
\hline & \multirow{2}{*}{ Family relations } & IT & 250 & 2.48 & .89 & \multirow{2}{*}{$-12.02 * * *$} & \multirow{2}{*}{346} \\
\hline & & IM & 98 & 3.89 & 1.17 & & \\
\hline & \multirow{2}{*}{ Religion } & IT & 250 & 1.94 & .94 & $024 * * *$ & 244 \\
\hline & & IM & 96 & 3.14 & 1.37 & 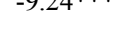 & 344 \\
\hline & Why of thinking (nrincinles and wolues) & IT & 250 & 2.18 & .88 & $1181 * * *$ & 345 \\
\hline & ways or tninking (principies and values) & IM & 97 & 3.59 & 1.24 & $-11.81+m$ & 345 \\
\hline
\end{tabular}

Note. Significant differences on t-test for independent samples. ${ }^{* * *} p<.001, * p<.05$. IT: Italians; IM: Immigrants

\section{RESULTS}

\subsection{General Acculturation Attitudes}

For both groups of participants, the deviation from the mean value (3) of the average scores for the two related questions of general acculturation attitudes obtained from onesample t-test, was reported. So, the Italians deviation from the average scores to the two questions in relation to the average value (3) was statistically significant (question 1, Maintenance, $M=2.83, t(246)=-2.52, p<.05$; question 2, Adoption, $M=$ $3.98, t(246)=19.79, p<.001)$, and it indicated a preference for the assimilation of immigrants. Considering the immigrants questioned, the variation of the average scores for the two questions with respect to the mean value (3) was statistically significant too (question $1, M=3.72, t(99)=7.23, p<.001$; question $2, M=4.02, t(99)=13.81, p<.001)$. These data indicated their preference for integration. Table 1 shows the average scores relate to general acculturation attitudes that immigrants and Italians claim to prefer.

The comparison of the general acculturation attitudes of Italians and immigrants (Table 1) shows a significant difference with respect to the maintenance of the original culture, $t(345)=-7.31, p<.001, d=.88$, with immigrants showing the highest average score in this dimension. There are not 
differences about cultural adoption (means above 3 in both groups).

\subsection{Acculturation Strategies (Real Plane) and Attitudes (Ideal Plane) in Specific Domains}

Real plane: Acculturation strategies. For each domain was calculated the deviation from the mean value (3) of participants' average scores of the two questions (cultural maintenance and adoption) (real plane), obtained from onesample t-test (Table 2).

There are statistically significant differences in both questions for both groups and for all the domains, except for religion (in the immigrant group and on adoption cultural question). This means that participants can be clearly placed in different acculturation strategies (put in practice or perceived) in all the domains, except religion (Fig. 1).

Table 3 reports the results of t-tests for independent samples for each specific dimension of culture maintenance and adoption on the real plane. The data show that, in most domains, Italians perceive that immigrants put separation into practice, with the exception of work (assimilation) and social relations (integration). However, immigrant participants declared putting into practice above all the integration strategy, except for the work domain (assimilation). Average scores show that Italians perceive that immigrants maintain their culture of origin especially in the central domains and social relations, in line with the declarations made by the immigrants. Shifting the focus on the adoption of the host culture, Italians perceived that immigrants adopted Italian culture especially in the peripheral domains, whereas immigrants claimed to adopt Italian culture especially in work and social relations.

As we can see in Table $\mathbf{3}$, significant differences between Italian and immigrant groups emerged in the maintenance of original culture in the following domains: social relations, $t(347)=5.90, p<.001, d=.65$, family relations, $t(346)=$ $-2.40, p<.05, d=.29$, and religion, $t(345)=4.44, p<.001, d=$ 47. Moreover, significant differences are also evident for the adoption of host culture in domains of work, $t(344)=.56, p<$ $.001, d=.67$, economic, $t(344)=-8.70, p<.001, d=1.02$, social relations, $t(347)=10.04, p<.001, d=1.20$, family relations, $t(346)=-12.02, p<.001, d=1.36$, religion, $t(344)=$ $-9.24, p<.001, d=1.02$, and ways of thinking (principles and values), $t(345)=-11.81, p<.001, d=1.31$.

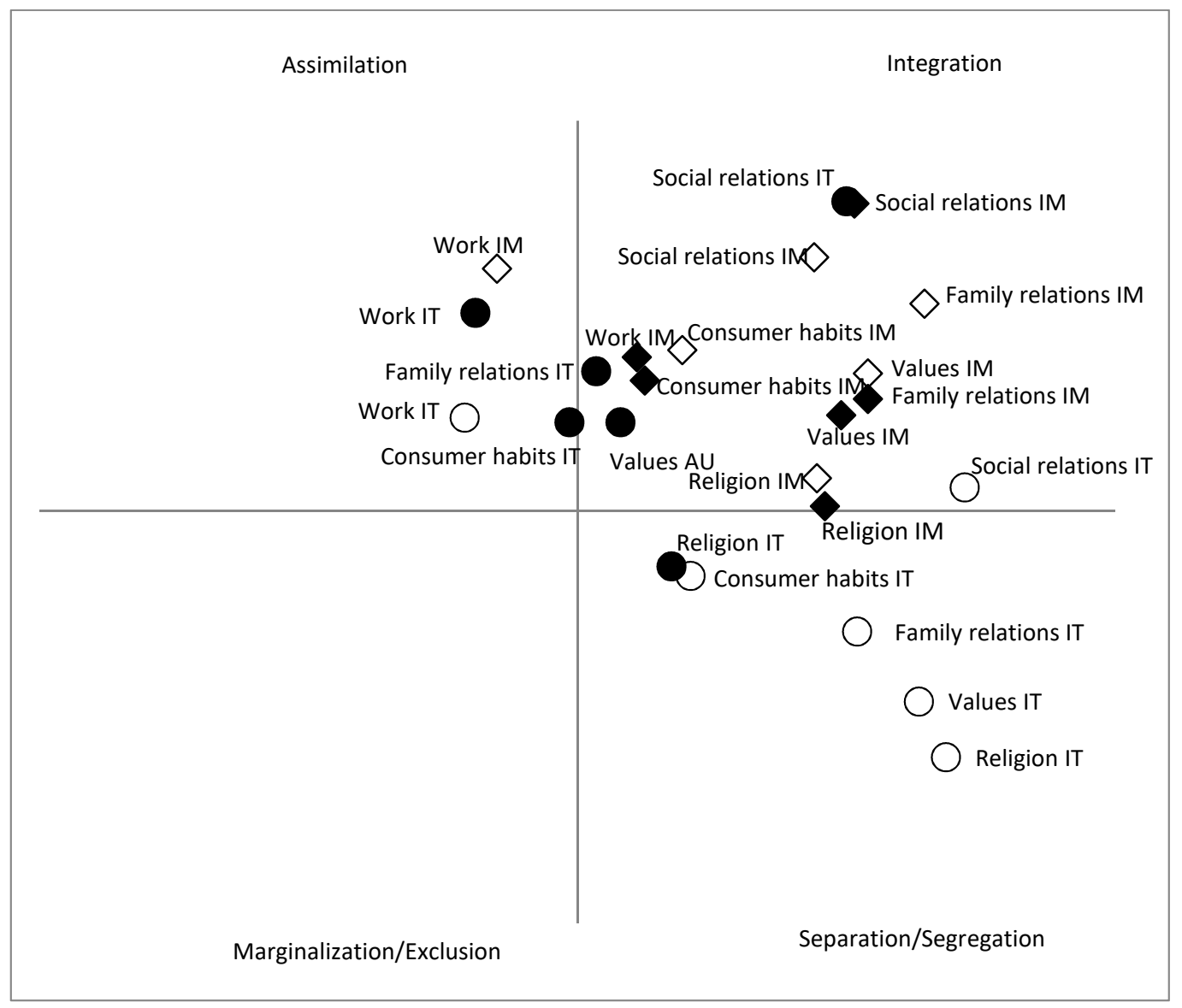

Fig. (1). Acculturation strategies (real plane) and attitudes (ideal plane) of Italian and Immigrant adults in specific life domains. Note. IT: Italians; IM: Immigrants

$\bigcirc$ Italians real plane; Italians ideal plane; $\diamond$ Immigrants real plane; $>$ Immigrants ideal plane 
Table 4. Descriptive analysis and one-sample t-test (value 3) of acculturation attitudes (ideal plane) by domains for Italian and Immigrant adults.

\begin{tabular}{|c|c|c|c|c|c|c|c|}
\hline Ideal Plane & Domains & Group & $N$ & $M$ & $S D$ & $t$ & $d f$ \\
\hline \multirow{12}{*}{ Maintenance } & \multirow{2}{*}{ Work } & IT & 250 & 2.62 & 1.14 & $-5.21 * * *$ & 249 \\
\hline & & IM & 98 & 3.22 & 1.23 & 1.81 & 98 \\
\hline & \multirow{2}{*}{ Economic } & IT & 250 & 2.97 & 1.06 & -.42 & 249 \\
\hline & & IM & 97 & 3.25 & 1.14 & 2.14 & 97 \\
\hline & \multirow{2}{*}{ Social relations } & IT & 250 & 4.00 & .89 & $17.67 * * *$ & 249 \\
\hline & & IM & 99 & 4.03 & 1.01 & $10.1 * * *$ & 99 \\
\hline & \multirow{2}{*}{ Family relations } & IT & 250 & 3.07 & 1.18 & .96 & 249 \\
\hline & & IM & 97 & 4.08 & 1.13 & $9.41 * * *$ & 97 \\
\hline & \multirow{2}{*}{ Religion } & IT & 250 & 3.35 & 1.22 & $4.6^{* * *}$ & 249 \\
\hline & & IM & 98 & 3.92 & 1.25 & $7.3 * * *$ & 99 \\
\hline & \multirow{2}{*}{ Ways of thinking (principles and values) } & IT & 250 & 3.16 & 1.12 & $2.19 *$ & 249 \\
\hline & & IM & 97 & 3.98 & 1.07 & $9.12^{* * *}$ & 99 \\
\hline \multirow{12}{*}{ Adoption } & \multirow{2}{*}{ Work } & IT & 250 & 3.85 & .93 & $14.45^{* * *}$ & 249 \\
\hline & & $\mathrm{IM}$ & 98 & 3.66 & 1.02 & $6.41 * * *$ & 98 \\
\hline & \multirow{2}{*}{ Economic } & IT & 250 & 3.38 & 1.00 & $6.02 * * *$ & 249 \\
\hline & & $\mathrm{IM}$ & 97 & 3.56 & 1.00 & $5.5^{* * *}$ & 97 \\
\hline & \multirow{2}{*}{ Social relations } & IT & 250 & 4.33 & .76 & $27.51 * * *$ & 249 \\
\hline & & IM & 99 & 4.32 & .70 & $18.9^{* * *}$ & 99 \\
\hline & \multirow{2}{*}{ Family relations } & IT & 250 & 3.60 & .99 & $9.6^{* * *}$ & 249 \\
\hline & & IM & 97 & 3.48 & 1.25 & $3.81 * * *$ & 97 \\
\hline & \multirow{2}{*}{ Religion } & IT & 250 & 2.76 & 1.26 & $-2.96 * *$ & 249 \\
\hline & & $\mathrm{IM}$ & 98 & 3.02 & 1.38 & .15 & 98 \\
\hline & \multirow{2}{*}{ Ways of thinking (principles and values) } & IT & 250 & 3.38 & 1.09 & $5.6^{* * * *}$ & 249 \\
\hline & & $\mathrm{IM}$ & 97 & 3.41 & 1.16 & $3.7 * * *$ & 99 \\
\hline
\end{tabular}

Note. T-test significant differences for one-sample. ${ }^{* *} p<.001 ; * * p<.01 ; * p<.05$; IT: Italians; IM: Immigrants

Ideal plane: Acculturation attitudes. For each domain was measured the deviation from the mean value (3) of participants' average scores of the two questions (cultural maintenance and adoption) of acculturation attitudes (ideal plane), obtained from one-sample t-test (Table 4).

For the Italian participants, there are statistically significant differences in both questions for all the domains, with the exception of economic and family relations in the question on cultural maintenance. Furthermore, for the immigrant participants, there are statistically significant differences in both questions for all the domains, with the exception of the work and economic (question on the maintenance) and religion (question on adoption). These results can be seen graphically in Fig. (1), where participants are placed in different acculturation preferences in those domains where there are statistically significant differences in both questions.

Table 5 shows the results of t-tests for independent samples for each specific dimension (maintenance and adoption) in each domain on the ideal plane (attitudes).

These data show that Italians preferred integration of immigrants in social relations, family relations and ways of thinking (principles and values) domains, whereas they preferred immigrants to be separate/segregate in religion domain. For the rest of domains (work and economic) Italians preferred immigrants to assimilate. Immigrants, however, ideally preferred integration in all domains (peripheral and central). So, Italian participants seem to prefer immigrants to maintain their culture in social relations and central domains, in line with the declared preferences of immigrants. Considering the adoption of the host culture, Italians preferred immigrants to adopt Italian culture in all domains (except religion), and immigrants claimed this too (including religion).

Significant differences between both groups emerged in relation to the preference to maintain the origin culture in the following domains: economic, $t(345)=-2.12, p<.001, d=.25$, family relations, $t(345)=-7.22, p<.001, d=.87$, religion, $t(346)=-3.87, p<.001, d=.46$, and ways of thinking (principles and values), $t(347)=-6.25, p<.001, d=.75$; whereas there were no significant differences in relation to the preference to adopt the Italian culture in any domain.

On the real plane (strategies), the comparison between Italians and immigrants showed differences especially in the "hard core" of the culture (family relations, religion and ways of thinking domains), since Italians have the perception that immigrants put into practice separation. On the contrary, on the ideal plane (attitudes), the comparison between the two groups of participants showed more similarities. From an intra-group perspective Italians seem to be incoherent about their perceptions (real plane) and their preferences (ideal plane) concerning immigrants; in fact, there is a big difference between the main preference of integration on the ideal plane and the perception that immigrants put into practice separation in central domains and assimilation or integration on the peripheral domains. On the other hand, immigrant participants 
Table 5. Descriptive analysis of acculturation attitudes for Italian and Immigrant adults in specific domains (ideal plane).

\begin{tabular}{|c|c|c|c|c|c|c|c|}
\hline Ideal Plane & Domains & Group & $N$ & $M$ & $S D$ & $t$ & $d f$ \\
\hline \multirow{12}{*}{ Maintenance } & \multirow{2}{*}{ Work } & IT & 250 & 2.62 & 1.14 & \multirow{2}{*}{-4.31} & \multirow{2}{*}{346} \\
\hline & & IM & 98 & 3.22 & 1.23 & & \\
\hline & \multirow{2}{*}{ Economic } & IT & 250 & 2.97 & 1.06 & \multirow{2}{*}{$-2.12 * * *$} & \multirow{2}{*}{345} \\
\hline & & IM & 97 & 3.25 & 1.14 & & \\
\hline & \multirow{2}{*}{ Social relations } & IT & 250 & 4.00 & .89 & \multirow{2}{*}{-.24} & \multirow{2}{*}{347} \\
\hline & & IM & 99 & 4.03 & 1.01 & & \\
\hline & \multirow{2}{*}{ Family relations } & IT & 250 & 3.07 & 1.18 & \multirow{2}{*}{$-7.22 * * *$} & \multirow{2}{*}{345} \\
\hline & & IM & 97 & 4.08 & 1.13 & & \\
\hline & \multirow{2}{*}{ Religion } & IT & 250 & 3.35 & 1.22 & \multirow{2}{*}{$-3.87 * * *$} & \multirow{2}{*}{346} \\
\hline & & IM & 98 & 3.92 & 1.25 & & \\
\hline & \multirow{2}{*}{ Ways of thinking (principles and values) } & IT & 250 & 3.16 & 1.12 & \multirow{2}{*}{$-6.25 * * *$} & \multirow{2}{*}{347} \\
\hline & & IM & 97 & 3.98 & 1.07 & & \\
\hline \multirow{12}{*}{ Adoption } & \multirow{2}{*}{ Work } & IT & 250 & 3.85 & .93 & \multirow{2}{*}{1.62} & \multirow{2}{*}{346} \\
\hline & & IM & 98 & 3.66 & 1.02 & & \\
\hline & \multirow{2}{*}{ Economic } & IT & 250 & 3.38 & 1.00 & \multirow{2}{*}{-1.43} & \multirow{2}{*}{345} \\
\hline & & IM & 97 & 3.56 & 1.00 & & \\
\hline & \multirow{2}{*}{ Social relations } & IT & 250 & 4.33 & .76 & \multirow{2}{*}{.05} & \multirow{2}{*}{347} \\
\hline & & IM & 99 & 4.32 & .70 & & \\
\hline & \multirow{2}{*}{ Family relations } & IT & 250 & 3.60 & .99 & \multirow{2}{*}{.90} & \multirow{2}{*}{345} \\
\hline & & IM & 97 & 3.48 & 1.25 & & \\
\hline & \multirow{2}{*}{ Religion } & IT & 250 & 2.76 & 1.26 & 166 & 346 \\
\hline & & IM & 98 & 3.02 & 1.38 & -1.66 & 346 \\
\hline & Wavs of thinking (nrincinles and values) & IT & 250 & 3.38 & 1.09 & -23 & 347 \\
\hline & & IM & 97 & 3.41 & 1.16 & -.23 & \\
\hline
\end{tabular}

Note. Significant differences on t-test for independent samples. ${ }^{* * *} p<.001$. IT: Italians; IM: Immigrants.

show wider coherence between strategies put into practice and attitudes preferred; in fact, integration is the main choice in the different domains for real and ideal plane.

Comparison between real and ideal planes. The average values for maintenance of original culture and adoption of the host culture, relative to the same acculturation domain, resumed in Tables $\mathbf{3}$ and $\mathbf{5}$ (real and ideal planes), were combined thus obtaining the acculturation options (strategies and attitudes) represented in Fig. (1) (X axis: cultural maintenance; $\mathrm{Y}$ axis: cultural adoption).

\section{DISCUSSION AND CONCLUSION}

The study aimed to know the acculturation process occurring in Italian and immigrant adults applying the RAEM [12 - 15]. This model allows to identify the general acculturation attitudes and moreover, to differentiate between acculturation strategies (real plane) and attitudes (ideal plane) in peripheral and central life domains, providing more and precise information about acculturation options from natives and immigrants perspectives. Considering the general acculturation attitude, it is possible to affirm that immigrant participants prefer integration, as already indicated by previous studies [4, 13, 33, 34], whereas Italians seemed to prefer assimilation for immigrants. This general acculturation attitude, according to Kosic, Mannetti and Sam [35], would be considered the least threatening by Italians, because it would mean the adoption of host culture by immigrants. This is justified by Van Oudenhoven and Hofstra [36] on the assumption of similarity-attraction, claiming that individuals prefer those who are perceived as similar to themselves or similar to their group in terms of attitudes, values, skills, etc. Similarity has the power to reduce interpersonal and intergroup insecurity. Specifically, cultural similarity is appreciated as it confirms the correctness and validity of their values and beliefs, and consequently, interaction too would be simpler. Therefore, it can be assumed, that $\mathrm{Hp} 1$ is confirmed, in line with the studies by Navas and colleagues $[13,14]$.

The present study also investigated whether the preferences expressed in the general acculturation attitude by Italian and immigrant participants change when take in account specific domains (work, economic, social relations, family relations, religion, ways of thinking -principles and values-).

On the real plane (acculturation strategies), immigrants claimed that they put the integration into practice in peripheral domains, except work (assimilation). Moreover, as argued by Navas and colleagues [14], immigrants tend to try to meet the expectations of the host society, but this happens only in domains where it is necessary (e.g. work, economic), and where their identity is not compromised. In fact, it should be noted that, although remaining in the area of integration, the scores in central domains in real plane indicate a greater inclination to maintain some specificities of their own cultures than those in peripheral domains, indicating the presence of some reserves in completely abandoning their customs. This was a notable difference compared with the Italians perceptions about the strategies used by immigrants. In fact, they perceive 
that immigrants try to keep their customs mostly by putting the strategy of separation into practice in one peripheral domain (economic) and in all central domains, and integration in social relations domain. The work domain differs as, in line with what immigrants reported, Italians perceive that they tend to assimilate into the host society.

The Italians perception that immigrants want to keep their own culture more than adopt the Italian culture, could have a double explanation. On one hand, it could be seen as a threat to their cultural identity and thus reduce their willingness to integrate $[37,38]$. On the other hand, not everyone feels threatened by this trend of immigrants. Much depends on the general inclination of individuals with regard to politics and multiculturalism $[39,40]$.

So, concerning immigrant participants, $\mathrm{Hp} 2$ on the real plane is only confirmed with respect to peripheral domains, for which a greater integration by the foreign population was expected. Whereas, with respect to the central ones, immigrants consider that they are integrated, by contrast with what was hypothesized. Regarding Italians participants, $\mathrm{Hp} 2$ is only confirmed in central domains (for which they perceive separation for immigrants), and in the work domain (where immigrants are perceived to assimilate to the host culture).

On the ideal plane, also $\mathrm{Hp} 2$ is partially confirmed. In fact, immigrants prefer integration especially in the peripheral life domains but also in the central ones, although the scores obtained were lower, showing caution in exclusively assuming new traditions (e.g., in religion domain). On the other hand, according to $\mathrm{Hp} 2$, natives prefer assimilation for immigrants in peripheral domains (work and economic) and separation for only one central domain (religion). However, they prefer integration of immigrants for social relations, family relations, and ways of thinking (principles and values) domains ( $\mathrm{Hp} 2$ is not confirmed in these cases).

As Zagefka and colleagues [40] illustrated, when the natives perceived that the members of the minority group wish to adopt their culture, the willingness to integrate was reinforced. This phenomenon occurs because the natives would be more willing to take a positive attitude and be open, sensing a positive slope towards the culture by the out-group. Moreover, the willingness to integrate would be determined also by consensual relationships created between the two groups that were in agreement with respect to acculturation orientations [5, 9].

Also, in this case, Hp2 was partially confirmed because, contrary to the results of Navas and colleagues [14], there does not seem to be an explicit tendency of immigrants towards separation in the central life domains.

The difference with the Spanish study could be explained by considering the participants' country of origin; in fact, the ones of the Spanish study come from Africa, whereas the ones of the present study come from different countries as like Albania, Ecuador, etc. Another explanation is possible as claimed by Brown [41], speaking only in terms of group size, the minority is more likely to have contact with the majority and not vice versa, and partially by the difference of life context and Italian immigration policies. Until the 1980s Spain and Italy were both emigration countries, and only in recent decades have they become the destination of intense immigration flows for which they are unprepared [42]. Last decades, the Italian model of integration has not been clearly defined yet, due to some laws that are pro-immigration and pro-integration (D. Lgs. n. 286/98 "Turco-Napolitano"), as claimed by the European Commission, but due also to other more restrictive laws (D. Lgs. n. 189/2002 "Bossi-Fini" and D. Lgs. n. 92/2008 "security package") concerning access to asylum processes, immigrants entrance to Italy and the duration of their stay for work [43]. However, in recent months the Italian situation is chancing because the Italian government's policies have chosen to close the ports even if these decision clash with a part of the public opinion. In recent years the Spanish government has been oriented towards welcoming the foreign presence as a potential resource both for the host country and their homelands [42].

Among the limitations of this study, should be stressed in particular that the native perspective only offers their perceptions about acculturation process affecting immigrants. However, this enabled gathering information with respect to the agreement and disagreement between the groups. An interesting future development of the study could be to obtain a direct measurement of the acculturation strategies used and attitudes desired by the native population, in order to complete the framework of intercultural relations in Italy. One more limitation concern the size of the sample, that is not representative and not equilibrated (among natives and immigrants), so further research could be conducted using a wider and more equilibrated sample. Furthermore, immigrant participants were considered as a single group, because there is no single characteristic that defines immigrants of a particular ethnic group [24]. Nevertheless, future application of the RAEM questionnaire may consider different ethnic groups separately to deepen the possible different acculturation strategies. Despite the limitations indicated, this work provides a psychosocial perspective on the acculturation process that is taking place between Italians and immigrants and indicates the life domains on which to intervene to improve intergroup relations in this context. In fact, the study of the acculturation process allows to identify the domains in which exist more differences between groups (as like family relations, religion or ways of thinking on the real plane) and suggest the potential existence of intergroup conflict [9] that should be kept in mind planning interventions empowering intergroup relations, for example in the school context to improve the relation between groups of the future adults. On the other way, the agreement between Italians and immigrant on the preferred acculturation options lead to identifying opportunities of harmonious life together, that governments could take advantage of. Those data could be taken into account to plan training in different contexts where intercultural relationships are becoming more and more important today. Furthermore, they can be useful for the governments to improve public services that take care of immigrant wellbeing, integration and intercultural relations.

\section{ETHICS APPROVAL AND CONSENT TO PARTICI- PATE}

Not applicable. 


\section{HUMAN AND ANIMAL RIGHTS}

No animals/humans were used for studies that are the basis of this research.

\section{CONSENT FOR PUBLICATION}

Not applicable.

\section{CONFLICT OF INTEREST}

The authors declare no conflict of interest, financial or otherwise.

\section{ACKNOWLEDGEMENTS}

The authors are especially grateful to the families for their willingness who freely and kindly gave their time.

\section{REFERENCES}

[1] Berry JW. A psychology of immigration. J Soc Issues 2001; 57(3): 615-31.

[http://dx.doi.org/10.1111/0022-4537.00231]

[2] Berry JW. Acculturation: Living successfully in two cultures. Int J Intercult Relat 2005; 29: 697-712.

[http://dx.doi.org/10.1016/j.ijintrel.2005.07.013]

[3] Redfield R, Linton R, Herskovits M. Memorandum on the study of acculturation. Am Anthropol 1936; 38: 149-52. [http://dx.doi.org/10.1525/aa.1936.38.1.02a00330]

[4] Berry JW. Immigration, acculturation and adaptation. Appl Psychol 1997; 46: 5-43.

[http://dx.doi.org/10.1111/j.1464-0597.1997.tb01087.x]

[5] Bourhis R, Moïse L, Perreault S, Senécal S. Towards an interactive acculturation model: A social psychological approach. Int J Psychol 1997; 32(6): 369-86.

[http://dx.doi.org/10.1080/002075997400629]

[6] Gordon MM. Assimilation in American life. New York: Oxford University Press 1964.

[7] Berry JW. Acculturation as varieties of adaptation.Acculturation: Theory, models and some new findings. Boulder, CO: Westview 1980; pp. 9-25.

[8] Berry JW. Conceptual approaches to acculturation.Acculturation. Washington, DC: Am Psychol Ass 2003; pp. 3-37.

[9] Piontkowski U, Rohman A, Florack A. Concordance of acculturation attitudes and perceived threat. Group Process Intergroup Relat 2002; 5(3): 221-32.

[http://dx.doi.org/10.1177/1368430202005003003]

[10] Arends-Tóth J, Van de Vijver FJR. Multiculturalism and acculturation: Views of Dutch and Turkish-Dutch. Eur J Soc Psychol 2003; 33 : 249-66.

[http://dx.doi.org/10.1002/ejsp.143]

[11] Arends-Tóth J, Van de Vijver FJR. Domains and dimensions in acculturation: Implicit theories of Turkish-Dutch. Int J Intercult Relat 2004; 28(1): 19-35.

[http://dx.doi.org/10.1016/j.ijintrel.2003.09.001]

[12] Navas M, García MC, Sánchez J, Rojas AJ, Pumares P, Fernández JS. Relative Acculturation Extended Model (RAEM): New contributions with regard to the study of acculturation. Int J Intercult Relat 2005; 29: 21-37.

[http://dx.doi.org/10.1016/j.ijintrel.2005.04.001]

[13] Navas M, García M, Rojas AJ. Acculturation strategies and attitudes of African immigrants in the South of Spain: Between reality and hope. Cross-Cultural Res 2006; 40(4): 331-51. [http://dx.doi.org/10.1177/1069397105283405

[14] Navas M, Rojas AJ, García M, Pumares P. Acculturation strategies and attitudes to the Relative Acculturation Extended Model (RAEM): The perspectives of natives versus immigrants. Int J Intercult Relat 2007; 31: 67-86.

\section{[http://dx.doi.org/10.1016/j.ijintrel.2006.08.002]}

[15] Navas M, Rojas AJ. Aplicación del Modelo Ampliado de Aculturacion Relativa (MAAR) a nuevos colectivos de inmigrantes en Andalucía: rumanos y ecuatorianos. Sevilla: Junta de Andalucía 2010. Application of the Relative Acculturation Extended Model (RAEM) to new immigrant groups in Andalusia: Romanians and Ecuadorians
[16] Miller MJ, Yang M, Lim RH, et al. A test of the domain-specific acculturation strategy hypothesis. Cultur Divers Ethnic Minor Psychol 2013; 19(1): 1-12.

[http://dx.doi.org/10.1037/a0030499] [PMID: 23148899]

[17] Miller MJ, Lim RH. The importance of acculturation and cultura values in counseling Asian American men.Culturally responsive counseling with Asian American men. New York, NY: Routledge 2010; pp. 39-62.

[18] Pérez Moreno PJ, Rojas Tejada AJ, Navas Luque M, Lozano Rojas OM. Structural model of acculturation attitudes and related psychosocial variables: empirical evidence in native Spaniards. Int J Psychol 2014; 49(3): 175-82.

[http://dx.doi.org/10.1002/ijop.12017] [PMID: 24821506]

[19] Celeste L, Brown R, Tip LK, Matera C. Acculturation is a two-way street: majority-minority perspectives of outgroup acculturation preferences and the mediating role of multiculturalism and threat. Int $\mathrm{J}$ Inter Relations 2014; 43(Part B): 304-20.

[http://dx.doi.org/10.1016/j.ijintrel.2014.10.002]

[20] Rania N, Migliorini L, Rebora S, Cardinali P. Daily family routine of Italian and Ecuadorian immigrant mothers in everyday life: A qualitative approach using diaries and interviews. SAGE Open 2015; 1-13.

[http://dx.doi.org/10.1177/2158244015609411]

[21] Migliorini L, Rania N. A qualitative method to "make visible" the world of intercultural relationships: The photovoice in social psychology. Qual Res Psychol 2017; 14(2): 131-45.

[22] Cicognani E, Sonn CC, Albanesi C, Zani B. Acculturation, social exclusion and resistance: Experiences of young Moroccans in Italy. International Journal of Intercultural Relations 2018; 66: 108-18.

[23] Migliorini L, Rania N, Tassara T, Cardinali P. Family routine behaviours and meaningful rituals: A comparison between Italian and migrant couples. Soc Behav Personal 2016; 44(1): 9-18.

[http://dx.doi.org/10.2224/sbp.2016.44.1.9]

[24] Rania N, Migliorini L, Rebora S. Parental competence in Italy: A comparison between italian and immigrant parents. Marriage Fam Rev 2018; 54(1): 1-14

[http://dx.doi.org/10.1080/01494929.2016.1247760]

[25] Matera C, Stefanile C, Brown R. Majority-minority acculturation preferences concordance as an antecedent of attitudes towards immigrants: The mediating role of perceived symbolic threat and metastereotypes. Int J Intercult Relat 2015; 45: 96-103.

[http://dx.doi.org/10.1016/j.ijintrel.2015.02.001]

[26] Mancini T, Bottura B. Acculturation processes and intercultura relations in peripheral and central domains among native Italian and migrant adolescents. An application of the Relative Acculturation Extended Model (RAEM). Int J Intercult Relat 2014; 40: 49-63. [http://dx.doi.org/10.1016/j.ijintrel.2013.12.002]

[27] López-Rodríguez L, Bottura B, Navas M, Mancini T. Acculturation strategies and attitudes in immigrant and host adolescents The RAEM in different national contexts. Psicol Soc 2015; 2: 133-57. [http://dx.doi.org/10.1482/77473]

[28] Matera C, Stefanile C, Brown R. The role of immigration acculturation preferences and generational status in determining intergroup attitudes. J Exp Soc Psychol 2011; 47: 776-85.

[http://dx.doi.org/10.1016/j.jesp.2011.03.007]

[29] Migliorini L, Rania N, Cardinali P. Acculturation strategies and adjustment in immigrant and host Italian communities. TPM Test Psychom Methodol Appl Psychol 2016; 23(1): 99-112. [http://dx.doi.org/10.4473/TPM23.1.7]

[30] Rania N, Migliorini L, Rebora S, Cardinali P. Enhancing critical dialogue about intercultural integration: The Photovoice technique. Int J Intercult Relat 2014; 41: 17-31.

[http://dx.doi.org/10.1016/j.ijintrel.2014.06.006]

[31] Rania N, Migliorini L, Cardinali P, Rebora S. Giving a face to immigration and integration processes: The use of Photovoice with Italian young adults. Qual Rep 2015; 20(6): 780-98.http://www.nova.edu/ssss/QR/QR20/6/rania4.pdf

[32] Matera C, Stefanile C, Brown R. Host culture Adoption or Intercultural Contact? Comparing different acculturation conceptualizations and their effects on host members' attitudes towards immigrants. Int J Intercult Relat 2012; 36: 459-71. [http://dx.doi.org/10.1016/j.ijintrel.2012.03.002]

[33] Van Oudenhoven JP, Prins KS, Buunk BP. Attitudes of minority and majority members towards adaptation of immigrants. Eur J Soc Psychol 1998; 28(6): 995-1013.

[http://dx.doi.org/10.1002/(SICI)1099-0992(1998110)28:6<995::AIDEJSP908>3.0.CO;2-8] 
[34] Zagefka H, Brown R. The relationship between acculturation strategies, relative fit and intergroup relations: Immigrant-majority relations in Germany. Eur J Soc Psychol 2002; 32: 171-88.

[http://dx.doi.org/10.1002/ejsp.73]

[35] Kosic A, Mannetti L, Sam DL. The role of majority attitudes towards outgroup in the perception of the acculturation strategies of immigrants. Int J Intercult Relat 2005; 29: 273-88. [http://dx.doi.org/10.1016/j.ijintrel.2005.06.004]

[36] Van Oudenhoven JP, Hofstra J. Personal reactions to 'strange' situations: Attachment styles and acculturation attitudes of immigrants and majority members. Int J Intercult Relat 2006; 30(6): 783-98.

[http://dx.doi.org/10.1016/j.ijintrel.2006.05.005]

[37] Stephan WG, Stephan CW. An integrated threat theory of prejudice.Reducing prejudice and discrimination. Hillsdale, NJ: Erlbaum 2000; pp. 23-45.

[38] Tip LK, Zagefka H, Gonzales R, Brown R, Cinnirella M, Na X. Is support for multiculturalism threatened by . . . threat itself? Int J
Intercult Relat 2012; 36: 22-30.

[http://dx.doi.org/10.1016/j.ijintrel.2010.09.011]

[39] Hindriks P, Verkuyten M, Coenders M. The evaluation of immigrants' political acculturation strategies. Int J Intercult Relat 2015; 47: 131-42. [http://dx.doi.org/10.1016/j.ijintrel.2015.04.002]

[40] Zagefka H, Tip LK, Gonzales R, Brown R, Cinnirella M. Predictors of majority members' acculturation preferences: Experimental evidence. J Exp Soc Psychol 2012; 48: 654-9.

[http://dx.doi.org/10.1016/j.jesp.2011.12.006]

[41] Brown RJ. Prejudice: Its social psychology. 2nd ed. Malden: Blackwell Publishing 2010.

[42] Noviello V. Politiche di integrazion en el contesto euromediterraneo 2010.http://www.issm.cnr.it/progetti/emigrazione/pubblicazioni/153_2 010 Noviello.pdf

[43] Zanfrini L, Monaci M, Sarli A, Mungiardi F. Country report Italy - At a (possible) turning point between constraining tradition and promising developments in the field of diversity. Milano: Fondazione ISMU 2015 .

\section{(C) 2019 Rania et al.}

This is an open access article distributed under the terms of the Creative Commons Attribution 4.0 International Public License (CC-BY 4.0), a copy of which is available at: https://creativecommons.org/licenses/by/4.0/legalcode. This license permits unrestricted use, distribution, and reproduction in any medium, provided the original author and source are credited. 